\title{
Pedagogical kinesiology in correctional work with preschool children with various disabilities
}

\author{
Inna Lukyanova ${ }^{1 *}$, Nadezhda Loshakova ${ }^{2}$, Evgeniy Sigida ${ }^{1}$, Svetlana Utenkova ${ }^{1}$, Farid Yunusov $^{3}$ \\ ${ }^{1}$ Moscow State Regional University, 141014, Mytishchi, Russia \\ ${ }^{2}$ Municipal preschool educational institution 65 "Swallow", 141021, Mytishchi, Russia \\ ${ }^{3}$ Russian Academy of Medical and Social Rehabilitation, 119634, Moscow, Russia
}

\begin{abstract}
In recent years, there is a growing number of children with speech disorders, including General speech underdevelopment (GSU). GSU children have problems with communication, development, and difficulties in working together with their peers. The use of kinesiological exercises complex in correctional and developmental work with preschool children is effective for the development of coherent speech and optimization of interpersonal relationships in the children's team.
\end{abstract}

\section{Introduction}

Speech disorders are connected with underdevelopment of mental processes (thinking, perception, attention, memory, etc.). Its provokes problems of coherent speech [6]. Speech disorders, motor skills, unbalance, and motor restlessness affect social and communicative function, and children have difficulties in joint activities with their peers $[1,5]$.

We use kinesiological methods in our correctional work with GSU children. Pedagogical kinesiology is defined as the science of mental development and physical recovery through motor exercises. They lead to the creation of new neural pathways and improve interhemispheric interaction. Unfortunately, there are no fundamental studies of their use in the correction of preschool children with GSU. And they are mostly referred to non-traditional methods of influence [7].

The relationship between human movements and thinking was noticed in ancient times. The beginning of the twentieth century is significant for the formation of a whole direction in research related to the action of muscles and the use of the identified patterns in the diagnosis of correctional and developmental kinesiological effects (doctorsspouses Kendall, osteopathic doctor J. Goodhart et al.). In the second half of the XX century, P. Dennison developed "brain Gymnastics". The basis of the method is the natural and effective possibility of developing mental processes through movements.

In Russian science, such prominent scientists as I. M. Sechenov, P. K. Anokhin, N. A. Bernstein, I. P. Pavlov, A. R. Luria, and others pointed out the interdependence of the mental and motor activity mechanisms development. Today, there are popular types of educational kinesiology. They use the relationship of muscle tone with the individual's psychoemotional state and stress level, formulate methods of corrective action within the framework of psychocorrection and body-oriented therapy [2]. The educational kinesiology was created on the basis of practical developments. It activates the functioning of the "body-intelligence" system, helps to develop the brain hemispheres in a balanced way [4].

\section{Materials and Methods}

The purpose of the organized empirical study was to test the effectiveness of experimental work with preschool children with GSU level 3 on the development of coherent speech and optimization of interpersonal relationships in the children's team using kinesiological methods.

The study was conducted in a pre-school educational institution among 10 preschool children with ONR level 3 ( 5 girls and 5 boys). As part of the study, the medical documentation (anamnesis data) was thoroughly studied and the results of the examination and the conclusion of the neurologist (neurological status) of children (I. U. Levchenko) were analyzed. Interpersonal relationships in the children's team were studied in the senior preschool speech therapy group, where these 10 children with level 3 GSU and 7 preschoolers with other speech development disabilities study. There are 8 girls and 9 boys in the group.

To perform the tasks of the empirical study, the following diagnostic tools were selected:

\footnotetext{
* Corresponding author: mpr-mgus@yandex.ru
} 
1. Examination of children's coherent speech (V. p. Glukhov). The goal is a comprehensive examination of the coherent speech of children with OND (level III speech development).

2. Sociometry " Choice in action "(ya. L. Kolominsky). Goal: to determine the preferred choices and their reciprocity. The child's speech and knowledge, his ability to navigate the surrounding reality. They provoke a variety of emotional and personal reactions, also depend on the developing relationships with peers [3].

\section{Results and Discussion}

A complete survey of children's coherent speech showed that most of the preschoolers had a low (40\%) or insufficient $(40 \%)$ level of coherent speech formation. The rest of the examined preschool children with a diagnosis of GSU 3 had a very low level of coherent speech formation (20\%). Medium and high levels were not observed.

For preschoolers with speech disorders, the status in a social group is also determined by the degree of their speech impairment, the ability to explain themselves in order to organize a common game or activity. The majority $(80 \%)$ of preschool children with level 3 GSU were neglected. They have $2-3$ choices by other children in the group. The rest $(20 \%)$ were outcasts with 1 choice. At the same time, children without a diagnosis of GSU 3 have 4 choices (57\%). Children with GSU communicate minimally with their peers and are not popular. Under equal external conditions, children of the preschool group preferred to accept children without a diagnosis of GSU in game. Preschoolers with GSU level 3 often play alone or are invited to common games and activities for secondary, uninteresting, passive roles.

Correction work was carried out for 4 months. A total of 18 classes were held. Each of the children in the experimental group attended at least 15 classes. The kinesiological methods system includes exercises of 3 groups: exercises that cross midline of the body, exercises that stretch the muscles of the body, exercises that increase the body's energy and further motivation, as well as additional special exercises for the development of coherent speech.

Each lesson includes several exercises from all 3 groups and groups of kinesiological exercises for the development of coherent speech in different order and combination. The lesson lasts 15-20 minutes.

Exercises were performed in the first half of the day; systematically, 3 times a week on Mondays, Wednesdays, Fridays; exercises were performed in a friendly environment; children were required to accurately perform movements and techniques.

The work was based on the principles of special psychological assistance.

The effectiveness of the system is confirmed by the change in the distribution of preschool children with GSU 3 at the levels of coherent speech development.

Before using the complex of kinesiological exercises in correctional work, the majority of preschool children showed a low level of coherent speech $(80 \%)$.

After using of kinesiological exercises in correctional work, $50 \%$ of children showed midium level of coherent speech development, only $10 \%$ low and $40 \%$ insufficient level of coherent speech development.

The dynamics of changes in the sociometric status of preschool children with level 3 GSU among other children in the group shows the transition of some children to a more privileged sociometric status. The changes are not yet very significant. The formation of a different intra-group interaction requires more time. The diagnostics recorded only a trend, and not the final result.

\section{Conclusions}

The system had a positive impact on the children's speech. They began to share their impressions of the classes, tell their parents about them. Further these children could clearly formulate the content of the lesson in combination with a partial display of exercises, which at the same time logically fit into the general scheme of the story. Parents noted the great organization and creative looseness of children. Children became smarter and more inquisitive. Teachers noticed that children with GSU level 3 became less irritable, and mutual discontent and resentment almost disappeared in the preschool group.

Teachers and parents noticed changes in the attitudes of children in the preschool group, more positive and equal perception of children by other preschoolers in the group. Free play began to cover the majority of children in the group. The teacher's interception for the general game organization has no need.

Children began to tell their parents more about game situations, finds, interesting characters modified by the children themselves. Preschoolers with level 3 GSU began to interact with each other, as well as with other children. The General psychological situation in the group becomes calmer, children are more active, interested, attentive to each other, and to teachers.

Thus, kinesiological exercises in correctional work with older preschoolers with GSU level 3 is effective for the development of coherent speech and optimization of interpersonal relationships in the children's team.

\section{References}

1. U.V. Gluzman, S.A. Gorodilova, N.N. Sheshukova, I.V. Andruseva, L.A. Guterman, Prospects of science and education, 4(46), 383-397 (2020) 
2. N.A. Kiyatova, Scientific forum: Pedagogy and psychology: collection of articles based on the materials of the XVI international conference. scientific-practical Conference ("MCNO", M., 3(16), 52-57, 2018)

3. A.S. Kuznetsov, Z.M. Kuznetsova, Russian Journal of Physical Education and Sport, 14(4), 5-7 (2019)

4. I.E. Lukyanova, E.A. Sigida, S.N. Utenkova, Child and adolescent rehabilitation, 2(34), 36-40 (2018)

5. E.S. Lyusova, Special education, XII, 95-99 (2016)

6. N.V. Rostovskaya, Young scientist, 20, 80-83 (2018)

7. L.A. Stupak, I.S. Ogorodova, A.A. Chelysheva, S.A. Kimyaeva, Actual problems of pedagogy: materials of the VII international conference. scientific Conference (Chita, April 2016) (Young scientist publishing House, Chita, 120-123, 2016) 